\title{
Medical Communications: The "Write" Career Path for You?
}

\author{
Yfke Hager \\ Gardiner-Caldwell Communications, an Ashfield company, Macclesfield SK11 7HQ, United Kingdom \\ Correspondence: yfke@cantab.net
}

\begin{abstract}
The pharmaceutical industry spends billions each year on the clinical development of new medicines. Getting those products to the patients who will benefit from them requires an ability to convey the results of extensive clinical research programs to regulatory authorities, physicians, and payers. Employed by medical communications agencies, contract research organizations, and pharmaceutical companies, medical writers distill and translate complex clinical and scientific data to develop documentation spanning the entire pharmaceuticalproduct life cycle, from clinical development to registration and marketing. Despite being a relatively new career, the market for medical communications professionals has doubled in recent years and future job prospects look promising.
\end{abstract}

$M$ dical communications offers two distinct career trajectories: editorial and account management. The editorial track, which is the most common track for those with a scientific bent, includes editorial assistants, medical editors, and medical writers, who are responsible for the development of all editorial content. They produce and/or manage the production of a wide range of materials, including newsletters, slide decks, posters, manuscripts, conference booth materials, websites, and electronic applications. After gaining some experience at a company, a medical writer can move into a management position, become a freelance writer, or move to a related career. Those in the account management track support the editorial team to ensure that projects are delivered on time, on budget, and in compliance with stringent industry guidelines and regulations.

The career path of medical communications blends scientific expertise with a passion for communication. Successful medical writers are excellent communicators, fast learners, sticklers for detail, and have a service-oriented mind-set. If you recognize yourself in this description, then perhaps it is time to throw off that lab coat and launch your medical writing career.

Over the past half century, scientific and medical knowledge has increased exponentially-so rapidly, in fact, that the originators of that knowledge (including scientists and medical doctors) began to struggle to communicate it effectively. Submitting a new drug to regulatory authorities for marketing approval involves the painstaking preparation of scientific documents so detailed and numerous that, until electronic submissions became the norm, they could quite literally fill entire trucks. The proliferation of promising drug targets in recent decades led to a boom in regulatory submissions and a definite shortage of people with the required skills to prepare this documenta-

Editors: Kaaren Janssen and Richard Sever

Additional Perspectives on Career Options for Biomedical Scientists available at www.cshperspectives.org

Copyright (C) 2019 Cold Spring Harbor Laboratory Press; all rights reserved; doi: a032953

Cite this article as Cold Spring Harb Perspect Biol 2019;11:a032953 
Y. Hager

tion. Medical writers stepped into the breach, deftly taking up the challenge to accurately disseminate biomedical information to a variety of audiences, whether charting the clinical development of a new drug for submission to healthcare authorities, drafting a clinical-trial report for publication in a medical journal, or preparing a slide presentation for a symposium at a scientific conference.

Medical writing may be a relatively new career, but the market has spread so quickly that medical writers can now be found in an astonishing variety of organizations. Medical writers are most commonly employed by medical communications agencies (also known as medical education agencies), contract research organizations (also known as clinical research organizations [CROs]), and pharmaceutical and biotechnology companies. However, many also find gainful employment in advertising or public relations agencies, hospitals or university medical centers, nonprofit organizations, medical or scientific publishing companies, and government agencies. This diversity of employers reflects the broad array of tasks that medical writers are expected to perform-all of which makes medical writing an exciting and varied career choice. Because the vast majority of medical writers launch their careers at one of the three main employer types-medical communications agencies, CROs, and pharmaceutical companies - this chapter focuses on them.

These three most common employers generally focus on three categories of medical writing: marketing, educational, and regulatory. Medical communications agencies such as Adelphi Communications, Complete Medical Group Worldwide, KnowledgePoint360 Group, Nucleus Global, and Ogilvy Healthworld tend to specialize in marketing and educational materials. Marketing materials are promotional in nature and explain the benefits of newly launched medicines or therapeutic agents, diagnostics, and devices to healthcare professionals such as physicians, nurses, and pharmacists. Materials may include slide presentations for stand-alone promotional meetings, scientific websites, webcasts, summaries of key clinical manuscripts or clinical case studies, interactive conference booth materials, and sales aids for pharmaceutical sales representatives. Educational materials are intended to inform a variety of audiences about the latest clinical trial results; these could include training manuals and product monographs. But educational materials can also be aimed at healthcare professionals: newsletters for investigators involved in clinical trials; posters and oral presentations at medical conferences; presentations for satellite symposia at medical conferences, advisory boards, and preceptorships; clinical manuscripts; and programs for continuing medical education (CME) activities. The work in communications agencies tends to be more creative than that at a CRO or pharmaceutical company, and is likely to suit those with commercial acumen who are driven by business objectives.

Whereas writers in medical communication agencies focus mostly on materials related to marketed products, those in pharmaceutical companies and CROs prepare materials describing products that are still in clinical development. Pharmaceutical and biotechnology companies include Abbott Laboratories, Amgen, AstraZeneca, Bayer HealthCare, BristolMyers Squibb, Eli Lilly, F. Hoffmann-La Roche, GlaxoSmithKline, Johnson \& Johnson, Merck \& Co, Novartis, Pfizer, and Sanofi. In general, medical writers at pharmaceutical companies write the regulatory documents required to obtain product marketing approval from international regulatory authorities such as the Food and Drug Administration (FDA) and the European Medicines Agency (EMA), but they are also responsible for developing a variety of other clinical documents supporting the approval process. These materials include clinical study protocols, clinical study reports, investigator brochures, periodic safety update reports, briefing documents for regulatory authorities, and responses to queries from regulatory authorities. CROs such as Charles River Laboratories, Covance, Parexel, Pharmaceutical Product Development (PPD), and Quintiles conduct clinical studies and assist pharmaceutical companies with regulatory submissions. Medical writers in CROs tend to prepare clinical and regulatory documents, but may also write manuscripts for publication in medical journals. 
Medical Communications Careers

Medical and scientific publishing is one of the fastest growing media sectors. Between 2003 and 2008, the medical writing market doubled from an estimated \$345 million to \$694 million, according to a CenterWatch report published in December 2008. Job prospects for technical writers, including medical writers, are expected to remain good in the coming years. According to the U.S. Bureau of Labor Statistics, employment of technical writers is expected to grow $17 \%$, about as fast as the average for all occupations, from 2010 to 2020. The U.S. Bureau of Labor Statistics attributes the rise in job opportunities to the ever-increasing complexity of medical and scientific information, and to the fact that significant continued growth in online publications and services will spur demand for writers and editors with expertise and experience in electronic media. Medical writing is a desirable and specialized skill set, which can only be honed by experience. It may be difficult to get a foot in the door, but those who manage to gain relevant on-the-job experience will find that they are truly a sought-after commodity. There are simply not enough experienced medical writers to fill the number of editorial roles available. As a result, salaries are compet- itive and have increased steadily over the past several years.

\section{JOBS}

Most medical communications agencies and CROs offer two distinct job tracks: editorial and account management/client services. However, some employers offer roles that combine aspects of both of these tracks. To understand the full range of possibilities, you should speak to people in different jobs and different companies and think carefully about the mix of responsibilities that would suit you best.

\section{Editorial Careers in Medical Communications Agencies and CROs}

Within medical communications agencies and CROs several editorial career paths exist (see Fig. 1). Editorial assistants support the editorial team; they do not produce medical or scientific content themselves, but they proofread and edit all materials produced by medical writers to apply consistent editorial style, check manuscript layouts, and perform general administrative editorial tasks, such as the electronic

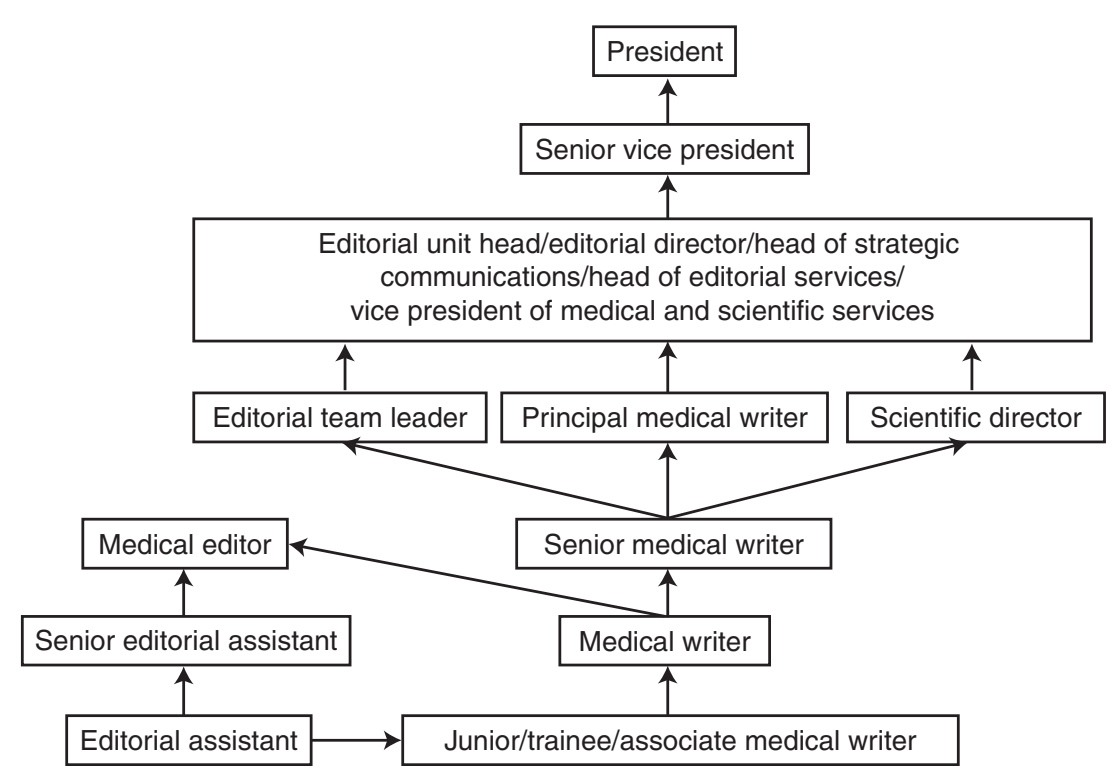

Figure 1. Typical editorial career structure. 
Y. Hager

submission of abstracts to medical conferences and manuscripts to medical journals. They also liaise closely with experts in other departments within the company (e.g., layout production artists, PowerPoint specialists, or electronic media specialists) to develop final print and electronic materials that meet client specifications. In larger companies, editorial assistants may have the opportunity to progress to the position of medical editor and senior medical editor. Medical editors are responsible for ensuring that all materials are completed to a high editorial standard in terms of both language and content. It is possible, although not very common, for editorial assistants to switch to medical writer positions, and for medical writers to switch to medical editor roles. Editorial assistants and medical writers can also transition to account management roles, although this is quite rare.

Most new recruits to the medical communications industry join as junior, trainee, or associate medical writers. Combining scientific knowledge and a flair for communication, medical writers translate the latest clinical trial results into language appropriate for a wide variety of audiences. They produce educational, promotional, and training materials for the healthcare industry and other end users. Although most of the work is office based, medical writing is not just a desk job. In medical communications agencies, some writers travel quite frequently to fine-tune slide decks for presentations by healthcare professionals at stand-alone or satellite meetings, or to take minutes at pharmaceutical industry meetings. More senior medical writers are expected to provide strategic input-for example, by developing annual communication plans or publication plans for specific products or business units. The editorial career path within agencies eventually leads to management positions, such as editorial unit head, vice president of medical and scientific services, or editorial director. Although the titles of these positions differ to reflect the naming conventions at individual companies, they tend to have similar duties, which are discussed in more detail in the section on career progression.

\section{Editorial Careers in Pharmaceutical Companies}

The editorial career structure in pharmaceutical companies is similar to that in medical communications agencies and CROs, with junior writers progressing first to senior and principal writer positions, then to managerial positions such as medical writing group manager, and finally to director of medical writing or head of clinical/scientific communications. At pharmaceutical companies, medical writers tend to work on complex regulatory documents, including clinical components of marketing authorization applications and briefing documents for interactions with healthcare authorities. At some pharmaceutical companies, medical writers also deliver study-level clinical documents such as clinical study protocols and clinical study reports.

\section{Account Management Careers}

A somewhat more linear career structure exists within account management (see Fig. 2). Project assistants provide general administrative

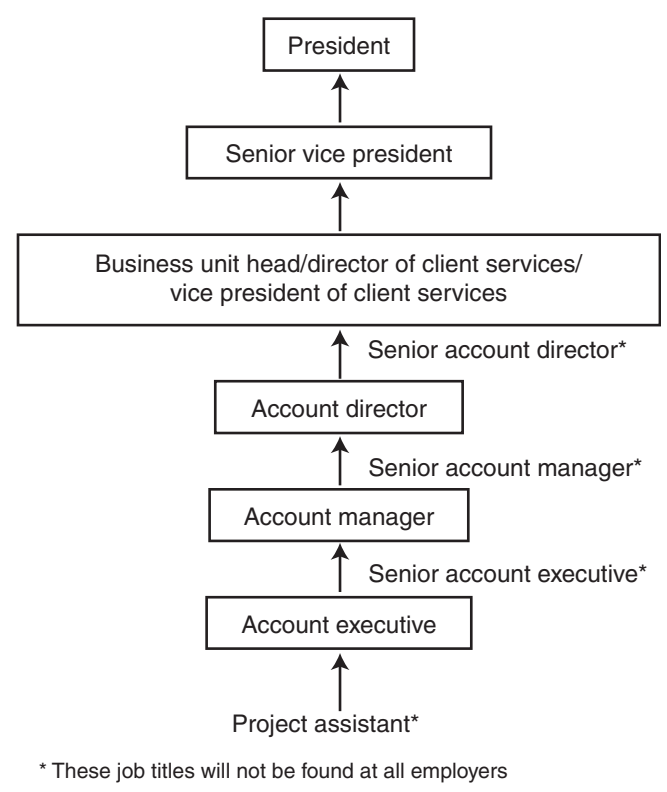

Figure 2. Typical account management career structure. 
Medical Communications Careers

support to project teams, often related to the logistics of event management such as satellite symposia at conferences, scientific preceptorship programs at hospitals, or advisory board meetings (at which pharmaceutical companies obtain advice on their clinical development programs from healthcare professionals who are recognized experts in their therapeutic area). Account executives, account managers, and account directors develop and manage client relationships for specific product accounts. They develop an understanding of client and product strategy and develop long-term communication plans to meet client needs. Next, they develop time lines, documents confirming the briefs received from clients, budget proposals and reconciliations, and are expected to maximize revenues and profitability within their accounts. The account management team provides guidance and leadership to the editorial delivery team to ensure that each project in the plan is produced in compliance with industry guidelines, and is delivered on schedule and on budget. In most companies, both editorial and account management staff have direct contact with clients. As with the editorial career track, the precise titles of senior roles in account management vary depending on the company.

\section{Executive Careers}

Both editorial and account management tracks can lead to executive positions within medical communications agencies or CROs. Senior vice presidents are generally responsible for an entire section or division of the company, with accountability for a large number of product teams. Depending on the size of the company, senior vice presidents may specialize in certain therapeutic areas or might work across several therapeutic areas. Their work often involves complex client negotiations, client appraisals, and winning new business. Finally, the president of an organization is responsible for the overall strategic and commercial development of the company, which involves keeping abreast of industry developments, identifying new business opportunities and directions for the company, and generally driving growth.

\section{SKILLS/QUALIFICATIONS}

The core skills required for a successful career in medical communications are broadly similar for both editorial and account management career tracks, although of course for an editorial role there is much greater emphasis on writing and research skills. Arguably of much greater importance is the difference in attributes that are required in the service industry (medical communications agencies and CROs) and those needed in the pharmaceutical industry, and this section is structured accordingly to help you identify the work environment that might suit you best.

\section{Core Attributes}

Established scientific credentials are important, particularly for editorial positions. Most employers look for life science graduates (biological science, pharmacy, pharmacology, chemistry, or biochemistry), but a small number of medical writers have a background in journalism or technical writing. Although an advanced degree (MSc, PhD) or postdoctoral experience is certainly advantageous, it is not essential. Former medical professionals are also welcome additions to any medical writing team. For account management positions scientific credentials are usually less important but are certainly advantageous, particularly for career progression.

It goes without saying that you will need excellent writing skills for editorial positions, so be prepared to provide evidence of an ability to produce high-quality scientific materials. You should also demonstrate enthusiasm and a keen interest in medicine and medical science, as you will be expected to learn quickly about different therapeutic areas on the job. A willingness to learn and flexibility are also traits that characterize good medical writers. Excellent research skills are essential, as medical writers are expected to assimilate large volumes of data. Good numeracy skills are also important-you do not need to be a mathematical expert, but you will need to have a good understanding of the more common statistical approaches used in clinical development. A keen eye for detail is vital; if the documents that 
Y. Hager

you produce do not represent the clinical data accurately, the consequences could be very serious indeed-errors could lead to compromised patient care, the rejection of a new drug application, lawsuits, or lost business for your company. In this field, being a pedant is a huge bonus.

Materials produced by medical writers must meet high ethical standards, so be prepared to learn about, and adhere to, strict industry regulations and guidelines. These include Good Publication Practice 2 (guidelines developed by the International Society for Medical Publication Professionals for responsible and ethical reporting of company-sponsored medical research) and the International Conference on Harmonization of Technical Requirements for Registration of Pharmaceuticals for Human Use (to ensure harmonized interpretation and application of technical guidelines and requirements for pharmaceutical-product registration). You will also be expected to undertake ongoing pharmaceutical-compliance training.

Finally, it helps to be thick skinned. At agencies and CROs, all work is subjected to quality control by senior editorial team members before going out the door, and then, it will be scrutinized by the clients. An ability to cope with and to use criticism to improve your work is absolutely essential.

Attributes of Particular Relevance to the Service Industry

How many medical writers does it take to change a lightbulb? If you answered "How many would the client like it to take?" you should give serious consideration to a job at an agency! It might sound obvious, but the single most important attribute for working in the service industry is a service-oriented mind-set. If you are considered an expert in your academic field and are accustomed to your opinion being valued, learning when to bite your tongue might be one of the most challenging aspects of your job. The scope and content of all projects are defined by your clients. Being a good listener and having an ability to interpret your client's requirements, instill confidence, and gain their trust is the key to a successful agency career.
The second most important attribute is outstanding time management skills. Sticking to budgeted time lines is of paramount importance in an agency - in fact, it is almost as important as the quality of the work itself. It will not matter that your project is perfectly crafted if it has taken twice as long to produce as your account manager has budgeted for. Closely linked to time management is the ability to multitask under pressure. If the thought of receiving dozens of emails and phone calls a day while trying to finalize a slide deck and negotiate with your production team to amend several posters in time for next week's medical conference terrifies you, working at an agency might not be for you. With experience, you will be expected to juggle multiple projects and reassess priorities on a daily basis.

Do not make the mistake of assuming that writers are loners stuck in a cubicle, tapping away at a keyboard all day. Depending on the agency and your role, you might be asked to travel extensively to medical congresses or to hospitals or hotels for stand-alone meetings. During these meetings, you will be expected to communicate confidently with senior healthcare professionals and pharmaceutical industry executives. Attending these meetings can certainly be exciting, but do not expect to get much sleep or to see much of the city where the event is being held. Be aware that promotional writing does not suit everyone. You will need to be familiar and comfortable with the commercial drivers behind the materials you produce. Agency life can be stressful, but the work is also fun, fast, and furious. It suits those who work best in teams, and you will find that the fast pace of the work also leads to a true sense of camaraderie within project teams, which can be quite rewarding. Finally, agency work is more creative and varied than clinical and regulatory writing — so if you get bored easily, an agency might be the right place for you.

\section{Attributes of Particular Relevance to the Pharmaceutical Industry}

When I moved from an agency to the pharmaceutical industry, I was initially surprised at the strong emphasis on leadership and project 
management skills during the interview process. But I soon discovered that a medical writing position within the pharmaceutical industry really is a leadership role. You are accountable for the timely delivery of large, complex clinical and regulatory documents that require input from people with a wide range of skill sets within the company, and you will be expected to lead cross-functional teams to deliver each project. That means working and negotiating with physicians, regulatory affairs managers, patient safety scientists, programmers, statisticians, pharmacometricians, and toxicology specialists. Due to the size and complexity of the documents, the pace of work is slower than that within agencies; each project can take months to complete, so strong project management skills are essential. Finally, problem-solving ability and decision-making skills are helpful attributes in this environment.

\section{GETTING A FOOT IN THE DOOR}

Ask any medical writer how they ended up working in this field and it is likely that serendipity will have featured at some point in their career path. But that does not mean that you cannot take proactive steps to forge a successful career in medical communications.

First, focus on activities that will help you demonstrate a passion for writing and communication in your job application. Join clubs or societies and volunteer for their communication or public relations (PR) positions. Submit articles to university newsletters, newspapers, or magazines. Enter science writing competitions. If all else fails, start a blog. Take advantage of opportunities to hone your oral presentation skills_-offer to lead a journal club or give a seminar in your department. Confident public speaking skills are a key requirement for many aspects of a medical writer's duties, including presenting to existing clients, pitching for new business, and negotiating with healthcare professionals. If you are willing to invest the time and money, consider enrolling for a journalism or science communication qualification. Not only will this help you stand out from the crowd and demonstrate that you are serious about pursuing a new career path, it will also help you determine whether you have the aptitude for a writing career. Some dedicated postgraduate courses are available, including one in biomedical writing at the University of the Sciences in Philadelphia and one in medical communications at the University of Worcester, United Kingdom. Finally, having any practical experience is of course an important asset, so consider contacting medical communications agencies or editorial/publishing houses to ask about internship opportunities.

Next, start identifying and researching possible employers and job vacancies. Use LinkedIn or other social networking sites to expand your professional network; try to connect with people working in medical communications and arrange informational interviews to learn about different roles and employers. Join relevant groups on LinkedIn (such as the MedComms Forum, Professional Medical/Scientific Writers, Science Writers, and The Publication Plan) and sign up to receive digests of discussions and jobs posted to these groups. This will help you build an awareness of relevant issues in the field. Because medical writers need to keep abreast of developments in medicine and medical communications, you can make a good impression in interviews by demonstrating an awareness of recent issues. Join the American Medical Writers Association (AMWA) or the European Medical Writers Association (EMWA) and attend their conferences-these offer excellent networking and educational opportunities, including workshops that will teach you valuable practical skills. Their member magazines and job listings are also useful resources. Finally, consider registering with specialist healthcare recruitment agencies. A good recruitment agent can educate you about the industry, match you to suitable companies, and support you through each step of the job application process.

Once you have decided to apply for a position, there are pitfalls to be avoided. Remember that your curriculum vitae $(\mathrm{CV})$ will be screened by a panel of editors and writers, so any typos or grammatical errors in your CV will end your medical writing career before it has even started. Do some background research so you can ask 
Y. Hager

knowledgeable questions; before an interview at a pharmaceutical company, find out about their research pipeline, and before an interview at an agency, make sure you know something about their therapeutic niche in the industry. It is very common for job applicants to be sent a writing test as part of the interview process, particularly those who are new to the field of medical communications. These tests can take various forms: you might be sent a medical poster or clinical manuscript and asked to draft the missing abstract, or you might receive a slide deck and be asked to select three to five key slides to print in an abstract book. Some employers might ask you to prepare a presentation on a given topic and deliver it to a small audience at your interview. There may also be an editing component to the test. The key to successfully completing any writing or editing test is to remember that you are not being assessed on your medical knowledge, but rather on your attention to detail, ability to follow a brief, and ability to construct a coherent and logical story.

Breaking into this world may well require some serendipity, but more importantly, it requires an ability to identify and sell your transferable skills to prospective employers. Many employers use behavioral interviewing techniques, where the job applicant is asked to describe situations in which they demonstrated particular qualities or attributes. You can prepare for these questions by considering detailed examples from your academic career, focusing on how your behavior and actions led to particular achievements. As examples of written and oral communication skill, consider your doctoral thesis, publications, conference presentations, and grant applications. To demonstrate project management skills, mention field courses you have led or student-club events you have organized. Teaching and tutoring duties might be a good source of examples of mentoring and people management skills, whereas any multilaboratory research collaborations can provide evidence of teamwork. Experience running a laboratory will also be valuable when you are asked about leadership qualities. Finally, almost any research project should provide excellent examples of problem-solving skills.

\section{CAREER PROGRESSION}

With about five to seven years of experience as an in-house writer with a given employer, a medical writer can progress by becoming a line manager, specializing in a particular therapeutic area, becoming a freelance writer, or making a lateral move to a different career track related to medical communications.

Associate medical writers generally progress to medical writer and then senior medical writer positions. At this point, there are usually three possible routes depending on whether the writer is interested in line management responsibility: principal medical writer, scientific director, or editorial team leader (see Fig. 1). Principal medical writers continue to focus on the delivery of editorial material, applying their extensive therapeutic area expertise to complex projects. Scientific directors are also involved in the development of editorial material, but they have a greater responsibility to provide strategic input and tend to specialize in a specific therapeutic area. Editorial team leaders have line management responsibilities, and are accountable for the quality of all editorial materials produced by a team of medical writers. Senior medical writers should try to gain experience mentoring junior writers to determine whether they have the right skill set and attributes for line management. Good editorial team leaders are extremely valuable to the company, and are always sought after.

With career progression into more senior positions, the boundaries between the editorial and account management career tracks become increasingly blurred, as tasks and responsibilities begin to overlap. Those in the editorial career track will be expected to increase their understanding of the financial aspects of the business, while those in account management will need to contribute to higher level discussions with clients and healthcare professionals, demonstrating a grasp of the scientific background and medical data underpinning the business strategy. Those in senior roles in both career tracks will prepare for and attend pitches to potential new clients, selling medical writing as a service to win new business for their com- 
pany. They will be involved in annual strategic communication planning for each product, project pricing and negotiation, writing proposals, as well as having financial responsibilities such as predicting revenues, meeting budget targets, and measuring team productivity. In addition to these project management duties, senior team members will also be expected to manage teams, which includes mentoring and guiding junior team members and conducting annual performance planning and reviews.

Working at a pharmaceutical company has a number of advantages when it comes to career progression. Because medical writing allows you to develop leadership skills and a detailed understanding of the entire clinical development process, it is an excellent gateway to other careers in the pharmaceutical industry, including positions in regulatory affairs, clinical research, medical information, document management, competitor intelligence, patient safety, and medical affairs. Most pharmaceutical companies encourage career progression within the business and are large enough to offer a range of different roles and internal transfer opportunities.

Not all writers are keen to move into management positions or remain at a company, working a typical 9-to-5 job. Becoming a freelance writer is a relatively common career choice, not only because it can be surprisingly lucrative, but also because it offers greater flexibility when it comes to work/life balance and the ability to choose your projects. However, a word of caution for new recruits hoping to break into medical writing as a freelancer: Clients will rarely, if ever, commission unknown or inexperienced freelance writers. For this reason, it is strongly advisable to gain significant experience (5-10 years) as an in-house writer at an agency, CRO, or pharmaceutical company before embarking on a freelance career. Those years spent learning the craft of medical writing are invaluable, allowing you to gain knowledge of different therapeutic areas, experience of developing a wide variety of materials, and an understanding of the financial aspects of the medical writing business. But most importantly, you will build a reliable network of healthcare professionals, pharmaceutical executives, and medical communications employees, essential for developing a strong client base for any freelance business. Successful freelance writers with entrepreneurial spirit might even consider starting up their own medical communications agency by employing other writers.

\section{WAY OUT}

Although most of this chapter is devoted to "traditional" medical communications, medical writers and account managers can use their specialist skill sets in a number of closely related areas. Making a lateral move is advisable when you feel that your current position no longer challenges you, or when you have identified an aspect of medical communications that you enjoy most and want to find a job that offers greater focus on that particular aspect of work.

For example, if you find preparing for and attending conferences and stand-alone meetings one of the most enjoyable aspects of your job, you could consider moving to an event management company, which specialize in logistical support for meetings and events. Lateral moves to companies specializing in PR or medical advertising might appeal to those who enjoy devising promotional campaigns and are less keen on writing data-heavy documents. Writers with a background or strong interest in economics and finance might wish to consider jobs at agencies specializing in health economics and outcomes research (HEOR), which involve the development of reimbursement strategies to demonstrate the clinical and economic value of pharmaceutical products.

For those who are interested in journal production or wish to focus on clinical publications (a term encompassing manuscripts, abstracts, posters, and oral presentations for conferences), medical or scientific publishing companies such as Elsevier or Wolters Kluwer Health offer related careers such as journal editor, production editor, or editorial director. Similarly, scientific publication managers working either in the pharmaceutical industry or at specialist companies are responsible for devel- 
Y. Hager

oping and delivering global publication plans to communicate the benefits of pharmaceutical products to healthcare professionals.

Gaining expertise across a range of therapeutic areas and experience with different types of medical writing are important if you want to remain competitive in the medical communications job market. So whatever role you are in and whatever employer you work for, make sure that your personal career development plan encompasses sufficient diversity to ensure career progression in this exciting and diverse field.

\section{BOX 1. My Experience}

Having completed a BA in Natural Sciences (Zoology) at the University of Cambridge, United Kingdom, I was full of enthusiasm about an academic career. I was lucky enough to gain the support of an excellent PhD supervisor who helped me navigate the maze of grants and bursaries available to European Union students at Cambridge (I am of Dutch/Belgian extraction). Because I had always enjoyed science communication, I spent a considerable amount of time traveling to schools and outdoor festivals to perform interactive science demonstrations for children as a volunteer for National Science Week and Cambridge Hands-On Science, a student-run group with the apt acronym CHaOS. I also started writing for the science page of Varsity, the student newspaper at Cambridge, where I discovered that I really enjoyed listening to scientists enthuse about their latest research.

Then a chance email changed the course of my career. While I was writing my PhD thesis, a bursary was advertised on a science communication mailing list. The winner would hold a temporary position as press officer for the Society for Experimental Biology (SEB), interviewing scientists and writing press releases for the SEB's annual main meeting. I won the bursary, and managed to convince my supervisor that this would be a month well spent. At the SEB conference, I met the news and views editor of the Journal of Experimental Biology (JEB), a scientific journal focused on comparative animal physiology. Using my SEB press releases to showcase my writing expertise, I persuaded the editor to commission me to write some freelance articles for the journal. This subsequently led to a position covering her maternity leave for a year, the start of which happily coincided with the submission of my PhD thesis. As the year was coming to an end I entered and won the Daily Telegraph Science Writer Award, a prestigious national science writing competition in the United Kingdom, which boosted my confidence and confirmed that I had chosen the right career path.

When my contract at the JEB ended, I moved to the North West of the United Kingdom to join my husband, who had started postdoctoral research at the University of Manchester. Through a contact from my SEB placement, I discovered that Cheshire is a hot spot for medical communications agencies, and successfully applied for a position as a trainee medical writer at a global medical communications agency. Some years later, I learned that it was the combination of my scientific background, experience at a scientific journal, and the Science Writer Award that helped me secure an interview and subsequently the job offer-it can be difficult to convince employers to take a chance on new recruits with no prior medical writing experience. The focus of the work was the delivery of educational and marketing materials for a blockbuster oncology drug. It was a steep learning curve, the work was varied and fun, and I enjoyed building good relationships with my colleagues, clients, and healthcare professionals.

After five and a half years, I decided that it was time to broaden my medical communications expertise beyond commercial writing. When a global biopharmaceutical company based in Cheshire advertised a vacancy in their medical communications department, I spoke to several Linkedln connections about their experiences in clinical and regulatory writing and decided to apply. Regulatory writing certainly broadened my perspective; during the first year, I worked on products in three different therapeutic areas. After two years, the company announced the imminent closure of its Cheshire site, so I moved back to a medical communications agency. I am confident that medical communications will continue to offer sufficient challenges for a long and happy career! 


\section{BOX 2. Ten Dos and Don'ts}

1. Do not submit a CV with typos or grammatical errors.

2. Do join the European Medical Writers Association (EMWA) or American Medical Writers Association (AMWA) and attend their conferences/workshops.

3. Do not give up too soon if you struggle to get a foot in the door; persevere and try to find an employer who is willing to train new recruits.

4. Do expand your network of contacts. Use Linkedln or other social networking sites to connect with people working in medical communications and join relevant discussion groups.

5. Do not forget to add scientific publications and conference presentations to your CV-they provide evidence of communications expertise.

6. Do arrange informational interviews with new contacts to find out more about specific companies and/or job roles.

7. Do not rule out companies based on location alone; some employers offer the possibility of working remotely.

8. Do send your CV to specialist healthcare recruitment agencies and ask for advice.

9. Do not be afraid to send speculative letters to potential employers and attempt writing tests to determine whether you have an aptitude for the job.

10. Do consider taking a writing or journalism course to gain experience, boost your CV, and demonstrate your commitment to a writing career. 


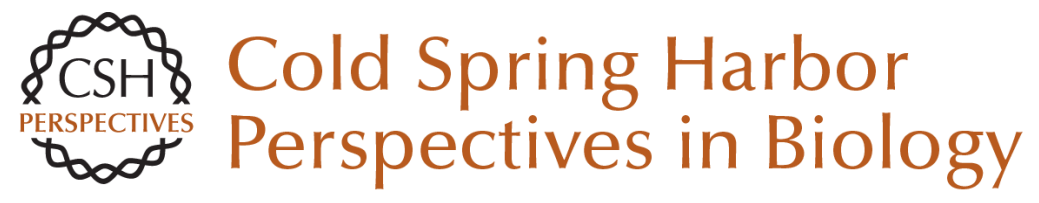

\section{Medical Communications: The "Write" Career Path for You?}

Yfke Hager

Cold Spring Harb Perspect Biol 2019; doi: 10.1101/cshperspect.a032953

Subject Collection Career Options for Biomedical Scientists

\section{Careers in Science Publishing} John R. Inglis

Medical Communications: The "Write" Career

Path for You? Yfke Hager

At the Crossroads of Science and Society: Careers in Science Policy Amy P. Patterson, Mary E. Groesch, Allan C. Shipp, et al.

A Career in Patent Law: At the Cutting Edge of Science, but Not at the Bench Salim Mamajiwalla

Careers in Science and Grant Administration: View from the National Institutes of Health Marion Zatz and Sherry Dupere

Careers at Biotech Start-Ups and in

Entrepreneurship Susan Froshauer

Careers in Science Journalism and Writing Helen Pearson

\author{
Careers in Academic Administration \\ Lydia Villa-Komaroff \\ Working for a Scientific Society \\ Martin Frank
A Career for Life Scientists in Management Consulting Rodney W. Zemmel \\ Careers in Core Facility Management \\ Claire M. Brown \\ Leaving the Bench and Finding Your Foundation \\ John E. Spiro
A Career at a Small Liberal Arts College Jennifer Punt \\ Career Options for Scientists \\ Richard Sever and Kaaren Janssen
}

For additional articles in this collection, see http://cshperspectives.cshlp.org/cgi/collection/

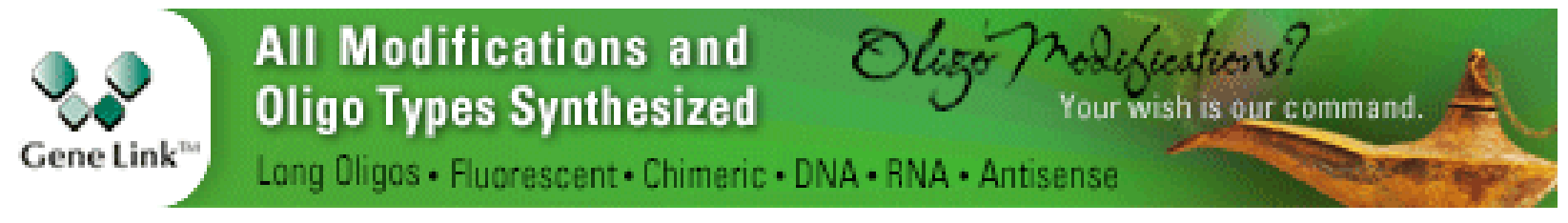

